\title{
The fictive personality revisited
}

\author{
Psychiatric admission as a consequence of \\ Princess Diana's death
}

\author{
Jill Chaloner
}

A 45-year-old woman with no previous psychiatric history had three psychiatric in-patient admissions with symptoms of suicidal ideation and depression which she attributed solely to the effect on her of Princess Diana's death.

The first admission occurred six weeks after the death. The patient reported going to pieces immediately after the death: she stopped cooking and house-work and let personal hygiene slip. Her mind became set on killing herself by taking pills or walking out in front of a vehicle in order to be with Princess Diana. Yet she described her interest in Diana as nothing out of the ordinary, and collected no memorabilia. She did not think of Diana when she was not on television but did try to watch her on television when broadcast. She was particularly upset by the way Diana was treated by the Royal family, viewing her as a victim of family unkindness. She admired Diana's work with charities and thought she was pretty, having once seen her at a film premiere in Leicester Square.

With regard to her own background, she was married with one son. She was of low average intelligence. Her parents divorced when she was 10 years old, with no contact with her father thereafter. There was difficulty with her stepfather and she had a male guardian until 16 and little contact with her siblings (all male).

During her two week admission she was completely preoccupied with the subject of Princess Diana and was unwilling to discuss her own life. She stated that Diana meant more to her than her son or her husband. She isolated herself on the ward, mixing neither with patients nor staff. Collateral history from relatives revealed major long-standing marital, financial and childcare problems. It was observed by staff that both her mother and her husband were extremely domineering, to the point of disregarding her completely when they were in her presence.

Following discharge she re-presented three weeks later, having threatened to take an overdose as she did not know how to live in a world without Diana. These thoughts had been triggered by a television programme about Diana.
There was a new adverse event in that her husband had lost his job. Nevertheless, she again was unwilling to discuss her own problems and talked mainly about Diana. A home visit carried out by the social worker revealed that the patient's home was dominated by photographs of the dead son of the husband by his first marriage. We also learned that her husband's first wife had been treated with electroconvulsive therapy in a psychiatric hospital for depression.

After less than a week she wished to be discharged but presented herself again six days later at the casualty department of the local district general hospital on Christmas Day with chest pain. When told by the casualty officer that she was fit to go, she said she would rather kill herself than go home. She then requested a psychiatric admission stating that she had not yet come to terms with Diana's death. She had watched a television programme about Diana before going to casualty. When assessed psychiatrically, although she stated she wished she were dead with Diana, she communicated directly her worries about her home life. This allowed very specific pieces of support to be offered in the form of debt counselling, marital therapy, childcare arrangements and attendance at a local women's group. With these in place she was discharged after a few days. When reviewed eight months later she reported herself able to watch television representations of Diana without any sense of distress.

The patient expressed herself in the language of bereavement. The lost person was, however, someone with whom she had had no personal interaction and whom she knew solely through media manipulated presentations. It was, on the other hand, evident that she was failing to influence or deal with the behaviour of those to whom she was closest. She gave an impression of not inhabiting her own life. Those around her were in a dominant position over her.

Instead of reflecting upon her dilemma, she projected aspects of herself into external phenomena encountered through television. In Kleinian terms, she projectively identified with Princess Diana's situation. She split bad and 
good by viewing Princess Diana as predominantly 'good' and the Royal Family (the Queen in particular) as 'bad'. She thereby denied the adverse events playing themselves out in her own life. At the reported death of Princess Diana she strove for a complete identification with the good object in death rather than take back into herself the previously projected good and bad parts of herself. By the third presentation. projective identification was largely abandoned. The patient somatised her anxiety by having chest pain, thus locating the problem inside rather than outside herself.

During her first two admissions, although the patient was striving to maintain denial, the ward team was constructing and presenting back to her an ever more accurate representation of her life as it actually was. This resulted in suggested measures to deal with the bad things. One might imagine that, by decreasing the badness of the bad objects, the need to split off and deny would be diminished. By the time Christmas Day arrived, a day associated with family celebration, the patient found a slightly different way to avoid the home situation and one which hinted at anger directed towards her family. Nevertheless, she continued to use the language of her projective identification even in recovery, since she was consciously aware only of her distress at Diana's death. She brought away from her hospitalisations no insight, self-knowledge or power to reflect on her own position. She would therefore remain vulnerable to utilise projective processes at times of emotional stress.

Jay Martin described in 1984 a personality disturbance which he called the fictive personality' in which 'the self strives towards total identification with characters in literary, historical, or mass-media fiction'. He cites examples from literature as when, in 18th century Germany, on reading Goethe's The Sorrows of Young Werther (Goethe, 1962) young men all over Europe committed suicide in identification with the main character. He cites the assassination of John Lennon by Mark David Chapman in which the killer identified with Holden Caulfield the main character of Salinger's (1951) novel The Catcher in the Rye, and John Hinckley who attempted to assassinate President Reagan while identifying with Travis Bickle, the hero of the Film Taxi Driver. Martin also describes clinical examples from his experience which greatly resemble my patient: people whose 'own ego appears impoverished or absent' to the extent that they can only keep themselves going through identifying with 'available fictions that fill up their empty selves and allow them to seem real so long as their fictions remain alive'. Martin links his own concept historically to Helene Deutsch's 'as if personality; Guntrip's 'schizoid emptiness'; Ann Freud's 'altruistic surrender' and Kohut's analysis of narcissism.

One could argue a further link with Winnicott's (1958) term 'transitional object' which describes the kind of attachment a child is capable of which is half way between living wholly in an inner world of fantasy and living wholly in the world of real human relationships. Toys with a special significance act as a safe repository for feelings. Images projected at us through the mass media may become 'transitional objects' for adults who have long since left that particular stage of emotional development behind.

It may be that the unremittingly present mass media as opposed to discrete works of art such as a novel or a film, make fictive personality disturbance more likely than ever before. Newspapers and television juxtapose thousands of representations through spoken or written words and still or moving pictures in a continuous flow which enters the home of every individual. There is a loss of any perceived boundary between 'real life' as lived and fictionalised life as represented. This was celebrated in McLuhan's notion of the 'global village' in the 1960s (McLuhan et al, 1967).

Currently, Oliver James (1998) has located the source of contemporary unhappiness and increasing use of antidepressants in it. He points out the vast numbers of represented, as opposed to actually known, individuals in the lives of all of us compared with people who have no access to the mass media. The balance is thereby shifted towards fictive, rather than real, relationships. Oliver James also notes the way in which, since human beings are naturally hierarchical, there is an accompanying increase in the numbers of upward and downward comparisons between the self and fictionalised persons as well as the self and real persons. This puts people into a position of enforced subordination, since media representations are often idealised, and thereby generates depression. He argues that even the Royal family is not exempt from the burden of self-comparison.

One might further argue that the low selfesteem and sense of stress generated by such a process would further increase the desire to live outside the self by projective processes. In turn. because fictionalised presentations of people outnumber real people, it would perhaps be more likely that a person would projectively identify with a fictionalised person than a real one, thus increasing the incidence of the disorder in society in general. To take this further still, relationships are now reported on the Internet between people who have created fictive personalities for themselves and who will never meet in the flesh. 
The mass response following Diana's death was reported in the psychological as well as in the national press as if it were a bereavement reaction or post-traumatic experience. This was challenged by Derek Summerfield (1998) a psychiatrist (working with victims of torture) who pointed out the difference between a real rather than imagined traumatic event. Thus, my patient's experience following Princess Diana's death represents a cultural as well as personal phenomenon. She found nothing unusual in the fact that a fantasised attachment to a famous individual known only through the media, held a higher value and stimulated stronger emotions than attachment to her family or friends. Since projective processes are continuously and actively encouraged by the nature and content of the mass media, it may be that fictive personality disturbance has now become a social norm which goes largely unremarked.

\section{References}

GOETHE, J. W. vON (1962) The Sorrows of Young Werther. In Selected Writings. (trans. C. Hutter) New York: New American Library.

JAMES, O. (1998) Britain on the Couch, pp. 42-127. London: Arrow Books Ltd.

McLuHAN, M., FIORE, Q. \& AGel, J. (1967) The Medium is the Massage. London: Penguin Press.

MARTIN, J. (1984) Clinical contributions to the theory of the fictive personality. Annual of Psychoanalysis 1984-85. vols 12-13, pp. 267-300. Beverly Hills. CA: South California Psychoanalytic Institute.

SALINGER, J. D. (1951) The Catcher in the Rye. London: Hamish Hamilton.

Summerfield, D. A. (1998) Princess Diana and posttraumatic stress (letter). British Journal of Psychiatry. 172, 364.

WinNicorr, D. W. (1958) Transitional objects and transitional phenomena. In Through Paediatrics to Psychoanalysis, pp. 229-242. London: Hogarth.

Jill Chaloner, Consultant Psychiatrist, Warley Hospital, Brentwood, Essex CM14 5 HQ

\section{Improving the Care of Elderly People with Mental Health Problems: Clinical Audit Project Examples \\ Kirsty MacLean Steel and Claire Palmer}

This new College Research Unit publication provides examples of clinical audit

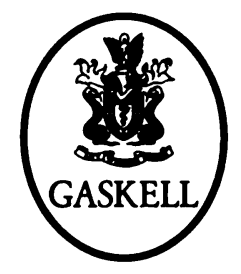
projects that have been performed within Old Age Mental Health Services. The projects have been divided into topic areas, and formatted into structured abstracts for ease of use. Clinical audit is an essential part of modern health care delivery and a core principal of clincial governance. This book contains a selection of clinical audit projects, all of which have been carried out in practice, with some still in progress. This book will be an invaluable guide for use in everyday practice.

\section{Features}

'Live' examples of clinical audit projects and advice from the people who carried out the clinical audits.

\section{Readership}

Old age psychiatrists, psychologists, clinical audit co-ordinators, nurses, quality \& effectiveness staff.

August 1999, £15.00, Paperback, ISBN 1901242382

Royal College of Psychiatrists, Book Sales, 17 Belgrave Square, London, SW 1 X 8PG Tel: 01712352351 ext 146, Fax: 0171245 1231, 9.30am - 2.00pm. 